\title{
Precarização e privatização das políticas públicas na educação a distância
}

\section{Precariousness and privatization of public policies in distance education}

\section{Miriam de Cassia do Carmo Mascarenhas Mattos}

Professora doutora no Centro Universitário Leonardo da Vinci, Indaial, Santa Catarina, Brasil. miriammattos@gmail.com - http://orcid.org/0000-0001-9597-987X

\section{Maria Cristina Rosa Fonseca da Silva}

Professora na Universidade do Estado de Santa Catarina, Florianópolis, Santa Catarina, Brasil. cristinaudesc@gmail.com - http://orcid.org/0000-0003-1571-9176

Recebido em 15 de outubro de 2018

Aprovado em 08 de dezembro de 2019

Publicado em 13 de maio de 2020

\section{RESUMO}

Estudo doutoral bibliográfico que contextualiza as políticas públicas no âmbito da educação e da EAD, refletindo sobre suas privatizações. Apresenta alguns estudos em nível internacional e relaciona os mesmos com as políticas no Brasil que se direcionam para a desresponsabilização do Estado. O financiamento da educação superior vem estimulando medidas que acentuam a privatização interna das instituições, ao mesmo tempo em que aprofunda o processo de empresariamento da educação superior, por meio da ampliação do número de cursos privados. Como exemplo, descreve e analisa o caso do grupo Kroton educacional, maior empresa na área em nível mundial e no ramo da EAD no Brasil. Seus resultados mostram que as políticas públicas educacionais têm favorecido as grandes empresas, que vêm lucrando ainda mais com a precarização da educação. Conclui que as mais recentes políticas de flexibilização vêm para favorecer o crescimento da EAD no Brasil, que pode ganhar um fortalecimento com o oferecimento do ensino médio nesta modalidade, aprovado recentemente, marcando assim uma conjuntura neoconservadora e de mercantilização da educação.

Palavras-chave: Educação à distância - EAD; Políticas públicas - EAD; Legislação EAD.

\section{ABSTRACT}

Bibliographical doctoral study that contextualizes the public policies in the scope of education and the EAD, reflecting on its privatizations. It presents some studies at the international level and relates them to the policies in Brazil that are directed towards the State's lack of responsibility. The financing of higher education has been 
stimulating measures that accentuate the internal privatization of institutions while at the same time deepening the process of entrepreneurship in higher education, through the expansion of the number of private courses. As an example, it describes and analyzes the case of the Kroton educational group, the largest company in the world wide area and in the branch of EAD in Brazil. Their results show that public educational policies have favored large companies, which have been making even greater profits from the precariousness of education. It concludes that the most recent flexibilization policies come to favor the growth of the EAD in Brazil, which can gain a strengthening with the offer of high school in this modality, recently approved, thus marking a neoconservative conjuncture and mercantilization of education.

Keywords: Distance education (EAD); Public policies - EAD; Legislation - EAD.

\section{Introdução}

O presente estudo trata-se de uma pesquisa bibliográfica ${ }^{1}$, parte de processo de doutoramento que, entre seus objetivos, investiga os modelos de formação desenvolvidos nos cursos de graduação na modalidade a distância, partindo das concepções que fundamentam a pedagogia histórico-crítica. Para isso foi necessário analisar os contextos internacionais, nacionais e as políticas públicas relacionadas à educação e seus reflexos na EAD.

Nessa etapa ${ }^{2}$, constatou-se a crescente participação de empresas na educação, como empreendimentos sociais, filantropia e no oferecimento de prestação de serviços nos mais diversos níveis. E, ao mesmo tempo, suas influências nas políticas educacionais, tanto diretamente, quanto indiretamente, em nível nacional e internacional.

No arcabouço teórico dessa pesquisa, conheceu-se a produção de Stephen J. Ball $^{3}$, em especial em seu livro "Educação Global S. A.: novas redes políticas e o imaginário neoliberal (BALL, 2014)", no qual pudemos aprofundar os caminhos desse processo. Os estudos do autor sobre as "políticas educacionais globais" vêm demonstrando a desnacionalização do Estado, com a disseminação de soluções privadas e do chamado "empreendedorismo social" na solução de problemas na educação pública. Suas pesquisas iniciam na Inglaterra, mas avançam para outros países e continentes como Índia, África, Ásia, América Latina, Estados Unidos, entre outros. Trata-se de uma análise "em rede e das redes", que envolve as mudanças das 


\section{Autตaหูão}

ISSN:1984-644 | http://dx.doi.org/10.5902/1984644435216

relações entre empresas, políticas educacionais e Estado Nação, bem como do papel da filantropia corporativa na resolução de problemas educacionais no Estado contemporâneo.

Além de Ball, pudemos também conhecer outras pesquisas que seguem a mesma linha, ou seja, o crescimento do privado sobre o público, com discursos que escamoteiam diversas fontes de lucro, nos mais diferentes países como: na Austrália (WINDLE , 2017) 5 e (DINHAM, 2015) ${ }^{6}$ no Chile (VERGER; BONAL; ZANCAJO, 2016) e (SCHNEIDER, 2014), na Inglaterra (HALL; GUTER, 2015), e no Brasil (AMARAL, 2016); e (ADRIÃO et al., 2009).

Ball (2014) observa a presença de uma nova elite de especialistas que sustentam um discurso neoliberal ideológico que vem ajudando a consolidar a "Multinational Education Businesses" - MNEBS, negócios educacionais multinacionais e transacionais, bem como as mudanças de relações entre empresas, políticas educacionais e Estado Nação. Para este autor, a análise da política educacional não pode ser limitada a um país, pois essas privatizações são complexas, multifacetadas e inter-relacionadas. Passam a envolver a venda de formação continuada, consultoria, treinamento, apoio, melhoria e serviços de gestão, bem como outros serviços técnicos, transformando a própria política pública em mercadoria, sendo a educação a distância mais uma faceta dessa prática.

\section{Fases da privatização das políticas públicas}

Detalhamos aqui de forma resumida algumas das "oportunidades de negócios" na educação, que inclui também novas formas da terceirização, contratação e parceria público-privada. Neste contexto, Ball (2014) destaca 3 fases principais desse processo, que ele nomeia de: Recalibração organizacional; Colonização das infraestruturas das políticas; Exportação e venda de políticas.

A recalibração organizacional envolve a venda da formação continuada, as consultorias, treinamentos, apoios, melhorias e serviços de gestão e serviços técnicos. Ball (2014) destaca empresas como a "Américas's Choice", que atua há mais de 10 anos, e recentemente foi comprada pela "Person Education", empresa bem 


\section{N Wrsm

conhecida no Brasil, principalmente no campo da EAD. O autor cita, também, a Cambridge Education; a Tribal; The Place Group e a Nord Anglia. Estas, por sua vez, apresentam métodos de ensino baseados em modelos de negócio e linguagem gerencialista. Tais empresas passaram a desenvolver e preparar testes, ao mesmo tempo em que fazem análise de dados e gestão, além de pesquisas que sustentam seus discursos de "ajuda e melhoria das escolas e da educação", contribuindo ideologicamente para mantê-las no 'grande esquema'. Nesta fase, "a privatização do setor público [...] não é feita retirando os serviços do controle do setor público, mas sim por meio de 'soluções' políticas e via colaborações de vários tipos com o setor público" (BALL. 2014, p.162).

A colonização das infraestruturas é a fase onde ocorre a $2^{\text {a }}$ camada das privatizações, com a produção de textos de políticas e de ideias, bem como com a exportação de "trabalho de Estado" a fornecedores privados e a agências. Decorrem disso novos discursos influenciados pelo setor privado operando dentro dos governos. Nesta fase,

A política em si é transformada em uma mercadoria em ambos os sentidos. Soluções políticas estão à venda e soluções tornam a política em um conjunto de calculabilidades, a prestação de serviços torna-se contratável e pode ser terceirizada. Para os negócios, há um círculo virtuoso entre a geração de conhecimento da política, a própria política e as novas oportunidades de lucro. (BALL, 2014, p. 163).

Esse processo fortalece a desresponsabilização do Estado em relação à educação, baseado em pressupostos neoliberais e articulados aos condicionamentos de novo reordenamento mundial. Ou seja, o poder público, como função reguladora, passa a conceber políticas educacionais focalizadas e fragmentadas, incentivando e transferindo responsabilidades do Estado para o setor privado e sociedade civil.

Para Schneider (2014), muitos países passam a ser pressionados por organismos multilaterais como o Banco Mundial ${ }^{7}$ e a Organização para a Cooperação e Desenvolvimento Econômico - OCDE, se tornando laboratórios de reformas educacionais sistemáticas. A autora destaca o sistema de Vouchers, adotado no Chile e também em diversos outros países. Esse sistema, onde os pais ou responsáveis 


\title{
N Wrsm

recebem um Voucher, ou seja, um valor em dinheiro ou vale que pode ser utilizado para escolher a escola onde seus filhos vão estudar, é um grande esquema de transferência de responsabilidade do Estado para entidades privadas de ensino. Schneider (2014) ainda afirma que o valor da subvenção que é pago às escolas privadas é o mesmo que recebem as escolas públicas municipais. Existem também modelos de escolas compartilhadas público privado, que recebem subvenção de forma diferenciada de acordo com o valor que cobram dos pais. Tal regime de financiamento fez com que proliferassem as escolas privadas subvencionadas e gerou (e está gerando) uma diminuição das matrículas no âmbito municipal (SCHNEIDER, 2014, p. 80).

Outros modelos fazem a privatização da gestão completa das escolas, quando consultores passam a organizar os procedimentos para admissão dos alunos, currículo das escolas, contratação de pessoal, além das instalações e finanças. Aqui os exemplos são as escolas nos modelos Montessori e escolas charter, modelo fortemente utilizado nos Estados Unidos. Hall e Gunter (2015) destacam que esse sistema educacional que substitui o modelo público pelo modelo privado faz com que as escolas passem a competir ferozmente, pois se trata de um mercado educacional onde os propósitos da educação são reduzidos a simplificações e a pontuações em testes.

\begin{abstract}
Nesse novo sistema de educação privatizado, a criatividade, a inovação e a autonomia estão localizadas nas novas liberdades desfrutadas pelos gestores escolares, que buscam posicionar suas instituições em mercados educacionais locais. O controle e a prescrição estão principalmente ligados ao ensino e à aprendizagem, sujeitando os jovens e os professores a uma camisa de força pedagógica focada no desempenho. A instabilidade permanente parece determinada a continuar. (HALL; GUNTER, 2015, p. 755).
\end{abstract}

$\mathrm{Na}$ terceira fase, as empresas passam a exportar e vender políticas. Como predadores, as edu-business, na busca de ampliação dos seus negócios, passam a operar em escala global. Para exemplificar, citamos a Cambridge Education ${ }^{8}$, que atua em mais de 60 países, entre eles: Tailândia, China, Hong Kong, Estados Unidos, Nova lorque, Guiné, Camboja e também no Brasil. Empresas como a Cambridge estão 


\section{Autตaหูão}

ISSN:1984-644 | http://dx.doi.org/10.5902/1984644435216

ansiosas para exportar seus produtos e conhecimentos de políticas e assumir as oportunidades dos processos de "reforma e de modernização do setor público" em países ao redor do mundo. Além disso, muitas destas políticas estão falidas em outros países e mesmo assim continuam sendo exportadas como promessa de melhoria.

Essa é a terceira camada do trabalho de política e de privatização. "[...] Há claramente agora algo que podemos chamar de 'política educacional global', um conjunto genérico de conceitos, de linguagens e de práticas que é reconhecível em várias formas e está à venda!" (BALL, 2014, p. 185).

\section{Educação à distância: o caso da Kroton educacional no Brasil}

A exemplo dos processos anteriormente descritos, a Educação a Distância também tem gerado um mercado muito lucrativo para empresas, principalmente aquelas que conseguem se capitalizar. A EAD é a modalidade de ensino que mais cresce no Brasil. Segundo dados do Instituto Nacional de Estudos e Pesquisas Educacionais Anísio Teixeira - INEP, vinculado ao Ministério da Educação - MEC (BRASIL; MEC; INEP, 2014), das 3,3 milhões de matrículas no ensino superior, registradas entre os anos de 2003 e 2013, um terço correspondia a cursos a distância, sendo a maioria na rede privada de ensino. De 49.911 alunos em 2003, o número saltou para 1.153.572 dez anos depois. Desse total, 86\% correspondia a instituições particulares de educação superior ${ }^{9}$. Em 2016 já representava 26\% da educação superior no Brasil, com a tendência de um crescimento massivo nos próximos anos (BRASIL; MEC; INEP, 2014). 


\section{Eutuapẫ}

ISSN:1984-644 | http://dx.doi.org/10.5902/1984644435216

Tabela 1 - Comparativo de matricula em EAD 2009-2013

\begin{tabular}{|c|c|c|c|c|c|c|c|c|c|}
\hline & & \multicolumn{7}{|c|}{ Número de Vínculos de Alunos } & \multirow[t]{4}{*}{ Total } \\
\hline & & \multicolumn{6}{|c|}{ CURSO A DISTÂNCIA } & \multirow[t]{3}{*}{ Total } & \\
\hline & & \multicolumn{3}{|c|}{ PÚBLICA } & \multirow[t]{2}{*}{ Total } & \multirow{2}{*}{\begin{tabular}{|l|} 
PRIVADA \\
PRIVADA \\
\end{tabular}} & \multirow[t]{2}{*}{ Total } & & \\
\hline & & FEDERAL & ESTADUAL & MUNICIPAL & & & & & \\
\hline $\begin{array}{l}\text { Ano } \\
\text { Censo }\end{array}$ & Grau Acadêmico & & & & & & & & \\
\hline \multirow[t]{3}{*}{2013} & BACHARELADO & 20.687 & 17.330 & 4.892 & 42.909 & 318.293 & 318.293 & 361.202 & 361.202 \\
\hline & LICENCIATURA & 65.901 & 29.532 & 2.363 & 97.796 & 353.397 & 353.397 & 451.193 & 451.193 \\
\hline & TECNOLÓGICO & 5.756 & 67 & 8.025 & 13.848 & 327.329 & 327.329 & 341.177 & 341.177 \\
\hline \multicolumn{2}{|r|}{ Total } & 92.344 & 46.929 & 15.280 & 154.553 & 999.019 & 999.019 & 1.153.572 & 1.153 .572 \\
\hline \multirow[t]{4}{*}{2009} & BACHARELADO & 16.795 & 41.333 & & 58.128 & 157.483 & 157.483 & 215.611 & 215.611 \\
\hline & LICENCIATURA & 57.350 & 39.839 & 32 & 97.221 & 322.408 & 322.408 & 419.629 & 419.629 \\
\hline & TECNOLÓGICO & 12.103 & 4.887 & 55 & 17.045 & 176.673 & 176.673 & 193.718 & 193.718 \\
\hline & $\begin{array}{l}\text { BACHARELADO E } \\
\text { LICENCIATURA }\end{array}$ & & & & & 7.636 & 7.636 & 7.636 & 7.636 \\
\hline & Total & 86.248 & 86.059 & 87 & 172.394 & 664.200 & 664.200 & 836.594 & 836.594 \\
\hline
\end{tabular}

Fonte: Inep (2014)

De acordo com a Sagah, empresa desenvolvedora de conteúdo e tecnologia para EAD, neste ritmo de crescimento, em 2023 o ensino superior a distância corresponderia a $51 \%$ do mercado (UNIVERSIA, 2016).

Mas isso ocorre ainda mais rápido, como divulgado pelo MEC em setembro de 2019, a partir dos dados do Censo da Educação superior de 2018. Destaca-se que a EAD teve 7,1 milhões de matrículas, enquanto a modalidade presencial teve 6,3 milhões. O número de cursos de educação à distância no país cresceu $50 \%$ em apenas um ano, passando de 2.018 para 3.177 , sendo a maior parte oferecida por universidades privadas, 12 milhões, contra 835 mil vagas por instituições públicas.

Os dados do Censo evidenciam, ainda, o domínio de alguns grupos educacionais privados no ensino superior à distância, com apenas cinco instituições particulares concentrando mais de $50 \%$ dos alunos que cursam EAD (BRASIL; MEC; INEP, 2018).

Dados como este têm incentivado muitas empresas e instituições a investirem nesta área. Porém, como exemplificaremos na sequência, algumas delas, gigantes do mercado, acabam diversificando e monopolizando todos os serviços da EAD, gerando muito lucro para seus mega-investimentos. Para isso, ao mesmo tempo, influenciam as políticas de governo e as políticas públicas, bem como a formação de professores e a formação dos alunos, gerando um círculo vicioso no qual só alguns têm vantagem. 


\section{Autตaหูão}

ISSN:1984-644 | http://dx.doi.org/10.5902/1984644435216

$\mathrm{Na}$ busca de exemplificar nossa afirmação, trazemos algumas informações sobre a Kroton educacional, maior empresa de educação em nível mundial e a maior empresa no ramo da EAD no Brasil. Em 2013, já era possível ter a dimensão desta organização, que já possuía mais de 35.000 funcionários, 726 polos divididos entre 11 marcas educacionais, distribuídas em todos os Estados Brasileiros. Neste mesmo ano, a Kroton registrava sozinha receita líquida de $\mathrm{R} \$ 674$ milhões, com alta de 34,9\% em relação ao mesmo período de 2013. Em 2017, após várias fusões, passou a contar com mais de $90 \%$ do mercado em EAD (OLIVEIRA; ROSTÁS, 2014).

Para conhecer um pouco mais do processo que levou a Kroton a ser essa gigante, buscamos várias fontes de informação na internet, encontrando inclusive algumas que utilizamos para ilustrar nossos estudos, mas a principal foi o próprio site da empresa ${ }^{10}$. Nele é descrita a trajetória da empresa, que apresentamos de forma resumida e posteriormente comentada.

Seu início deu-se no ano de 1966, em Belo Horizonte, com a parceria entre 5 jovens amigos que ousaram montar um empreendimento na área de educação: o curso vestibular Pitágoras. Em dois anos, seu microempreendimento já tinha mais de 600 alunos, distribuídos em 13 turmas em três turnos. Em apenas 6 anos eles fundaram o colégio Pitágoras, ampliando seu público para 5 mil alunos (KROTON, 2017).

Na década de 1980 a Pitágoras juntou-se com "uma tradicional construtora"11 "que preparava-se para iniciar 2 imensas obras de infraestrutura, uma no Iraque e outra na Mauritânia". A Pitágoras, passou então, a atuar dirigindo unidades escolares que possuíam mais de mil alunos brasileiros nesses países. Já nos anos de 1990 é criada a rede Pitágoras, que "em menos de 1 ano, já contava com 106 escolas associadas" (KROTON, 2017). E, em 1999, foi criada a Fundação Pitágoras, para viabilizar projetos educacionais em instituições públicas e privadas. Segundo o site, a fundação buscava "perenizar a organização".

No início dos anos 2000, é fundada a primeira Faculdade Pitágoras, em parceria com uma das maiores companhias de educação do mundo, a Apollo International, com sede no Arizona, nos Estados Unidos. Tal parceria durou até 2005, 


\section{Autตaหูão}

ISSN:1984-644 | http://dx.doi.org/10.5902/1984644435216

quando a Apollo International decidiu vender sua participação aos fundadores. No ano de 2007, a empresa entra no mercado de capitais na BM\&FBovespa, com o nome Kroton Educacional (KROT11). E, em 2009, a Kroton recebeu um novo aporte financeiro de um dos maiores fundos de private equity do mundo, a Advent International, que a partir de então compartilharia o controle da Companhia com os sócios fundadores.

Em 2010, a Kroton efetuou a maior aquisição do setor de educação superior do Brasil ao comprar a IUNI Educacional, instituição que oferece programas de graduação e pós-graduação sob as marcas UNIC, UNIME e FAMA. E em 2011 adquire a Faculdade Atenas Maranhense (São Luís e Imperatriz - MA) e Faculdade União (Ponta Grossa - PR). Em novembro deste mesmo ano, realizou uma nova aquisição a FAIS - Faculdade do Sorriso. Em dezembro, realizou a maior aquisição da história da educação, a UNOPAR, e tornou-se líder no setor de educação a distância do Brasil. No ano seguinte, 2012, adquiriu Centro Universitário Cândido Rondon (Unirondon). E, em maio, realizou a aquisição da Uniasselvi, fortalecendo sua liderança na Educação a Distância.

Em 2013 expandiu abrindo 40 novos Polos de Graduação a Distância com o nome de Unopar. Neste mesmo ano, é anunciado acordo de associação entre a Kroton e a Anhanguera, para formar a maior empresa de educação do mundo.

Quando vemos histórias como a da Kroton, muitas vezes estas nos são passadas como modelos de empreendedorismo, de muito trabalho, e aproveitamento de oportunidades. Mas a realidade é que experiências assim estão eivadas de superexploração, precarização, e utilização de recursos públicos através, por exemplo, do Fundo de Financiamento Estudantil - FIES, e do Programa Universidade para Todos - ProUni, projetos que tornaram investimentos como o da Kroton de baixo risco, com lucro certo e inadimplência quase nula, pois o Governo paga a faculdade e o aluno tem até 18 meses para começar a devolver o dinheiro investido a longo prazo. Além disso, o ProUni proporciona bolsas de estudos que estas instituições abatem de seus impostos. Segundo Campos (2014), a Anhanguera, por exemplo, tinha 40\% das matrículas novas realizadas através do Fies. 


\section{N

ISSN:1984-644 | http://dx.doi.org/10.5902/1984644435216

Como força motriz dos investimentos públicos do Governo Dilma Rousseff, programas como o Fies e o ProUni deram à Kroton em 2014, antes mesmo da fusão com a Anhanguera, 201,9 mil novas matrículas em graduações somente no $1^{\circ}$ trimestre, representando um aumento de $15,1 \%$ em relação ao mesmo período do ano anterior. Em termos de rematrículas, os registros atingiram 390,2 mil alunos na graduação durante o $1^{\circ}$ trimestre, alta de $29,7 \%$. [...] À medida que esses grupos seguem a lógica do mercado financeiro, a preocupação com ensino de qualidade é zero. Contratação de professores pouco qualificados, aumento desenfreado do ensino à distância, ausência de laboratórios e nenhum projeto de pesquisa são algumas das suas especialidades. Além do papel estratégico da educação para o desenvolvimento do país e os direitos de estudantes e trabalhadores, que são substituídos pela busca por lucro. (CAMPOS, 2014).

Campos (2014) afirma que tanto a Kroton, quanto a Anhanguera (lembrando que agora já fazem parte do mesmo grupo), ofertam 1/3 da grade curricular de todos os cursos em disciplinas on-line. Essas economias, no entanto, muitas vezes não são repassadas na hora da cobrança das mensalidades e muito menos para seus funcionários. Segundo Daniel Cara (2014), coordenador geral da Campanha Nacional Pelo Direito a Educação ${ }^{12}$, "as instituições de ensino superior credenciadas para receber recursos do Fies, vêm reajustando as mensalidades bem acima dos aumentos promovidos pelas universidades que não contam com essa linha de crédito". Em média, essa diferença tem girado em torno de 2,5\% ao ano, mas há cursos, como os de medicina, em que o aumento adicional chega a 9,3\%, ou seja, "os alunos estão se endividando para pagar cursos cada vez mais caros", afirma Cara (2014).

Com esses recursos que saem diretamente dos cofres do governo, são alimentadas as estruturas dessas gigantes multinacionais que, no Brasil, já superam as matrículas em universidades federais.

No quadro abaixo, resumimos a trajetória da Kroton, lembrando que as pesquisas apresentadas por Ball e diversos outros autores mostram que este não é um caso isolado.

Quadro 1: trajetória da empresa Kroton Educacional

\begin{tabular}{|l|l|}
\hline $\mathbf{1 9 6 6}$ & Inicia como curso vestibular Pitágoras - 600 alunos \\
\hline $\mathbf{1 9 6 8}$ & Se transforma em colégio Pitágoras - 5.000 alunos \\
\hline $\mathbf{1 9 8 0}$ & Parceria com construtora com atuação no Iraque e Mauritânia - 1000 alunos no exterior \\
\hline $\mathbf{1 9 9 0}$ & Criação da rede Pitágoras - 106 escolas associadas \\
\hline
\end{tabular}




\section{Eilloa \\ ISSN: 1984-6444

ISSN:1984-644 |http://dx.doi.org/10.5902/1984644435216

Quadro 1: trajetória da empresa Kroton Educacional

\begin{tabular}{|l|l|}
\hline 1999 & Criação da Fundação Pitágoras - projetos educacionais público e privado \\
\hline $\mathbf{2 0 0 0}$ & Parceria com Apollo International \\
\hline $\mathbf{2 0 0 5}$ & Fusão internacional compra Apollo International \\
\hline $\mathbf{2 0 0 7}$ & Entra no mercado de capitais BM\&F BOVESPA e muda de nome para Kroton \\
\hline $\mathbf{2 0 0 9}$ & Recebe aporte financeiro internacional do Private Equity Advent \\
\hline $\mathbf{2 0 1 0}$ & Compra a IUNI que já incorporava: UNIC, UNIME e FAMA \\
\hline $\mathbf{2 0 1 1}$ & $\begin{array}{l}\text { Compra várias instituições: faculdade Atenas; União; Fais; Unopar e torna-se a maior } \\
\text { empresa educacional do Brasil }\end{array}$ \\
\hline $\mathbf{2 0 1 2}$ & Compra a Unirondon e a Uniasselvi, tornando-se a maior no ramo da EAD do Brasil \\
\hline $\mathbf{2 0 1 3}$ & $\begin{array}{l}\text { Abre mais } 40 \text { polos em EAD com o nome UNOPAR } \\
\text { Se funde com a Anhanguera, tornando-se a maior empresa de educação do mundo }\end{array}$ \\
\hline
\end{tabular}

Fonte: elaborada pela autora com base no site (KROTON, 2017).

(conclusão)

Estas empresas, com trajetória inicial pelo domínio local, e expansão nacional e internacional, passam a diversificar suas ações e entram no mercado de capitais. Além disso, não bastando os lucros obtidos dos serviços privados oferecidos, criam fundações "sem fins lucrativos" 13 que atuam em escolas e universidades públicas. Isso antes e depois de subsidiarem campanhas políticas ${ }^{14}$, que pressionam a modificação de marcos regulatórios, influenciando nas políticas públicas e políticas de governo. Estes, por sua vez, fragilizam essas políticas e permitem inclusive a monopolização dos serviços, mesmo que de forma escamoteada nos processos jurídicos oficiais.

Ao mesmo tempo, percebemos um discurso das diversas vantagens dessa modalidade promovido por organismos internacionais ${ }^{15}$, oferecendo respostas flexíveis e personalizadas a uma diversidade cada vez maior de tipos de informação, educação e treinamento, por meio da atualização rápida do conhecimento técnico. Com essas recomendações, a EAD é vendida como uma alternativa para o Estado no que se refere à possibilidade de expansão do ensino e racionalização de recursos. Essa campanha, somada às políticas públicas em prol da $E A D$, vem funcionando muito bem para as empresas. 


\section{Usism

\section{Políticas públicas na EAD: algumas considerações sobre o contexto brasileiro}

Poderíamos iniciar este texto resgatando as origens e todo o histórico da EAD, que datam do início do século XX no Brasil, com as iniciativas de escolas internacionais, os modelos por correspondência, além do papel das rádios e dos programas educativos da TV (ALVES, 2009). Ou ainda detalhar as primeiras iniciativas de governo neste campo no Brasil. ${ }^{16}$ Mas, por opção, já que podemos verificar esse histórico de forma detalhada em diversos documentos, e como não se trata do foco desse trabalho, nosso recorte inicia desde a década de 1990 até os dias atuais.

Para Malanchen (2007), foi neste período que as políticas públicas em EAD e a formação docente foram redesenhadas, se colocando em consonância com as diretrizes de organismos internacionais - Ol. Esses interesses se articulavam aos das corporações transnacionais que, por sua vez, tinham o objetivo de garantir e potencializar o "incessante movimento de acumulação do capital, de forma mundializada, mediante a construção do ideário das relações reguladas pelos princípios do livre mercado". (MALANCHEN, 2007, p. 19).

A autora também destaca o contexto político de governo, sendo sua gênese, consolidação e expansão atribuídas principalmente a dois mandatos presidenciais: 0 de Fernando Henrique Cardoso (1995- 2001), que consolidou essas políticas, e o de Luiz Inácio Lula da Silva (2002-2006), que a expandiu. E como veremos adiante neste artigo, fortalecido pela flexibilização da EAD no governo Temer.

De acordo com Malanchen, na década de 1990 o cenário brasileiro passava por profundas mudanças, pois precisava reorganizar suas políticas devido à complexidade das relações internacionais. Diante disso, o Brasil foi orientado pelas políticas de ajuste estrutural empreendidas pelo Banco Mundial - BM, a diversificar as instituições de ensino superior, e desta forma organiza-se um campo lucrativo para o setor privado. O BM ainda recomendava que as instituições públicas diversificassem as suas fontes de financiamento para que não fossem dependentes exclusivamente do Tesouro do Estado (MALANCHEN, 2007, p. 35). 
Essa reforma estaria embasada na diferenciação institucional e na diversificação das fontes de financiamento das instituições de ensino superior, vinculadas ao objetivo de reduzir gastos do Estado. O Banco justifica que só implantando essa reforma o Brasil teria condições de ter êxito no novo mundo resultante das mudanças nos sistemas produtivos (BM, 1995).

\begin{abstract}
Nesses termos, o BM orienta que a educação precisa difundir novas habilidades para os trabalhadores atingidos pela reestruturação do mundo do trabalho, efetivar a expansão continuada do conhecimento e ampliar, em menos tempo, o número de indivíduos com acesso ao ensino superior. $\mathrm{O}$ Banco recomenda que, para ser formado o novo trabalhador, seja implantada a EAD e por meio dela utilize-se as TIC. Em diversos trechos do documento de 1995, o BM orienta que a EAD deve ser utilizada principalmente na formação docente inicial e continuada e relata diversas experiências de países como Chile, Tailândia e outros, nos quais os resultados, segundo o Banco, foram positivos. (MALANCHEN, 2007, p. 35).
\end{abstract}

Para Nunes e Silva (2014, p. 1085), no que se refere à discussão sobre as políticas educacionais a partir da década de 1990, houve um aumento crescente de pesquisas voltadas a esse campo específico de conhecimento da EAD. Esses estudos tiveram como preocupação central a influência dos Organismos Internacionais Banco Mundial - BM, Fundo Monetário Internacional - FMI; Comissão Econômica para a América Latina e o Caribe - Cepal, dentre outros na regulação dessas políticas no contexto das reformas educacionais. Mesmas percepções tiveram Adrião et al. (2009, p. 800) ao constatar o aumento significativo da delegação de responsabilidades do setor público para o privado, a partir no final do século $X X$, generalizando-se para muito além de modalidades específicas, a partir de uma profunda reforma do Estado brasileiro, posta em curso na década de 1990. Tal reforma, como resposta a uma suposta crise de eficácia da administração pública, propõe a adoção da administração gerencial.

Malanchem (2007) problematiza a questão a partir das diretrizes oriundas dos Organismos Internacionais, que foram efetivadas com o consenso de órgãos do governo na reformulação da política educacional no Brasil, com pressupostos de ampliação de acesso à Educação Básica, de diversificação das instituições de ensino 


\title{
Autตaหูão
}

ISSN:1984-644 | http://dx.doi.org/10.5902/1984644435216

superior e de seus cursos e a diversificação das fontes de financiamento desse nível de ensino. Esses elementos, segundo a autora,

\begin{abstract}
são apresentados como significativos para a criação de um engodo de democratização e do aumento de escolarização, mascarando dois fenômenos que vêm ocorrendo nos países periféricos: o aligeiramento da formação inicial e o processo de certificação em larga escala (MALANCHEN, 2007, p. 22).
\end{abstract}

Nesse contexto, emergiu abriu um nicho de mercado para a iniciativa privada na EAD como um todo, mais especialmente na formação de professores do ensino básico. A formação docente passou a ser realizada não apenas nas universidades, mas, preferencialmente, nos Institutos Superiores de Educação - ISE. Isso ocorre em consonância com documentos, principalmente do Banco Mundial (BM), que sugerem que a formação docente não precisa ocorrer necessariamente na universidade, mas pode ser realizada em ISEs ou à distância e em qualquer outro tipo de instituição, alimentando o ideário sobre EAD.

Chagas (2013) ressalta, ainda, alguns documentos elaborados pela Organização das Nações Unidas para a Educação, a Ciência e a Cultura (Unesco), que objetivavam tratar a expansão do ensino superior que vinha ocorrendo na América Latina ao mesmo tempo que estimulavam a EAD no ensino superior e com a mesma lógica privatista e mercadológica da educação. "Desta forma, a meta central que perpassou esses documentos se assentava na perspectiva de ampliação do acesso ao ensino superior, objetivando 'incluir' o segmento dos trabalhadores nesse espaço universitário" (CHAGAS, 2013, p. 7). Deste modo, a realidade da sociedade passou a ser configurada a partir das orientações do Banco Mundial, com uma ampliação das universidades privadas, e com a reestruturação das universidades públicas.

O Estado passa, então, a defender e legitimar a educação à distância como uma modalidade de ensino capaz de suprir a falta de escolaridade, através da ampliação do acesso para todos. Entretanto, afirma Chagas, 


\section{Autตaหูão}

ISSN:1984-644 | http://dx.doi.org/10.5902/1984644435216

O padrão que se imprime na formação superior atual está longe de se pautar em um modelo de excelência na qualidade e procura apenas a inserção de cada vez mais alunos, para manter a lógica lucrativa para o capital, considerando que tais cursos estão na esfera privada (CHAGAS, 2013, p. 8).

Nesta direção, Lima (2008) analisa a EAD a partir da desresponsabilização do Estado, sustentando que o financiamento da educação superior estimula medidas que acentuam a privatização interna das instituições de ensino superior - IES, ao mesmo tempo que aprofunda o processo de empresariamento da educação superior, por meio da ampliação do número de cursos privados, e se utiliza de uma lógica empresarial à formação profissional, reduzindo o tempo de duração dos cursos e não se contrapondo à precarização do trabalho docente.

\section{Considerações finais}

Os marcos regulatórios da EAD no Brasil não foram tratados diretamente nesse artigo por serem objeto específico em outra produção teórica, mas é importante destacar que, em 25 de maio de 2017, ocorreu a nova regulamentação da Educação a Distância a partir do Decreto nำ 9.057/2017, (BRASIL, 2017) publicada na edição do Diário Oficial da União (e retificado em 30/05/2017, em seu artigo 9o que versa sobre a oferta de ensino fundamental na modalidade a distância em situações emergenciais). A partir deste decreto, as instituições de ensino superior passam a poder ampliar a oferta de cursos superiores de graduação e pós-graduação a distância, sendo permitido que as próprias instituições façam o credenciamento da modalidade EaD sem exigir o credenciamento prévio para a oferta presencial. Assim, as instituições poderão oferecer, exclusivamente, cursos a distância, sem a oferta simultânea de cursos presenciais.

No site do MEC, consta de quem é a estratégia é a ampliação da oferta de ensino superior no País, buscando atingir a Meta 12 do Plano Nacional de Educação - PNE, "que exige elevar a taxa bruta de matrícula na educação superior para $50 \%$ e a taxa líquida em 33\% da população de 18 e 24 anos" (BRASIL, MEC, 2017). 


\section{Autตaดูão}

ISSN:1984-644 | http://dx.doi.org/10.5902/1984644435216

Essa nova legislação define também que as pós-graduações lato sensu EaD ficam autorizadas para as instituições de ensino superior que obtenham o credenciamento EAD, sem necessidade de credenciamento específico, tal como a modalidade presencial. Também prevê que os cursos nessa modalidade poderão ter as atividades presenciais realizadas em locais distintos da sede ou dos polos de educação a distância.

Em relação à oferta de cursos superiores na modalidade a distância, serão admitidas parcerias entre a instituição de ensino credenciada para educação a distância e outras pessoas jurídicas, preferencialmente em instalações da instituição de ensino, exclusivamente para fins de funcionamento de polo de educação a distância, desde que formalizadas e designadas as obrigações das entidades parceiras. Neste caso, será

responsabilidade exclusiva da instituição de ensino credenciada para educação a distância ofertante do curso quanto a: I - prática de atos acadêmicos referentes ao objeto da parceria; II - corpo docente; III - tutores; IV - material didático; e V - expedição das titulações conferidas" (BRASIL, 2017).

Além disso, também regulamenta a oferta de cursos a distância para o ensino médio e para a educação profissional técnica de nível médio, devendo essas modalidades atenderem ao Novo Ensino Médio. Mas, neste caso, ainda terão seus critérios definidos pelo MEC em conjunto com sistemas de ensino, Conselho Nacional de Educação - CNE, conselhos estaduais e distrital de educação e secretarias de educação estaduais e distrital, para aprovação de instituições que desejam ofertar educação a distância (BRASIL, MEC, 2017).

Esse destaque foi importante para sustentar que essa política pública atual de flexibilização favorece o crescimento da EAD no Brasil, ampliando sua abrangência inclusive para o ensino médio, e marca uma conjuntura de mercantilização da educação. Saviani (2016) classifica tal política de flexibilização de "abastardamento da educação", que inclui um pacote de medidas contra o povo como: cortes e congelamento do orçamento, que ficará estagnado por 20 anos; fim da vinculação 


\section{Autตaหูão}

ISSN:1984-644 | http://dx.doi.org/10.5902/1984644435216

constitucional dos recursos para educação e saúde. Além, é claro, da reforma trabalhista que atinge também os professores.

Vivemos um momento histórico no qual as propostas neoconservadoras vêm se fortalecendo e ganhando todos os espaços de disputa nas políticas públicas. $\mathrm{Na}$ educação, como exemplo, destacamos o "novo ensino médio" e agora "a flexibilização da EAD".

Não bastasse isso, Saviani (2016, p. 391) lembra do movimento denominado "Escola sem partido", que vem se apresentando na forma de projetos de lei na Câmara dos Deputados, no Senado Federal e em várias assembleias estaduais e câmaras municipais do País. O referido projeto é chamado por seus críticos de "lei da mordaça", pois explicita uma série de restrições ao exercício docente, negando o princípio da autonomia didática consagrado na legislação e nas normas relativas ao funcionamento do ensino.

Assim, concluímos que, nesta etapa de pesquisa, foi possível evidenciar o efeito nocivo da mercantilização da educação como um todo, e da EaD em particular, bem como o processo acelerado de precarização e privatização da educação, com aval do Estado e das suas políticas públicas, fortalecendo sua desresponsabilização junto aos processos educacionais.

\section{Referências}

ADRIÃO T.; et al. Uma modalidade peculiar de privatização da educação pública: a aquisição de "sistemas de ensino" por municípios paulistas. Educ. Soc., Campinas, v. 30, n. 108, p. 799-818, out. 2009.

ALVES, J. R. M. A história da EAD no Brasil. 2009 In: LITTO, F. M.; FORMIGA M. M. M. (Orgs.). Educação a distância: o estado da arte, São Paulo: São Paulo: Pearson Education do Brasil, 2009.

\section{AMARAL, N. C. Com a PEC 241/55 (PEC 95) haverá prioridade para cumprir as metas do PNE 2014-2024? [s.l, s.n] 2016.}

BALL, S. J. Educação Global S. A.: Novas redes políticas e o imaginário neoliberal. Trad. Janete Bridon. Ponta Grossa: UEPG, 2014. 
BANCO MUNDIAL. Construir sociedades del conocimiento: nuevos retos para la educación terciária. Washington, D.C.: Banco Mundial, 2003. Disponível em www.obancomundical.org.ar/. Acesso em: 02 maio 2018.

\section{BANCO MUNDIAL. Estratégia do Banco Mundial para a educação na América}

Latina e no Caribe, 1999. Disponível em: http://www.bancomundial.org. Acesso em: 20 out. 2006.

BANCO MUNDIAL. La Enseñanza Superior: las lecciones derivadas de la experiencia. Banco Mundial. Primeira Edição em Espanhol, junho de 1995. Washington-DC.

BRASIL; MEC; INEP. Censo do ensino superior no Brasil. 2014. Disponível em: http://inepdata.inep.gov.br/. Acesso em: 5 jun. 2017.

BRASIL; MEC; INEP. Censo do ensino superior no Brasil. 2018. Disponível em: <http://inep.gov.br/web/guest/sinopses-estatisticas>. Acesso em: 5 set. 2019.

BRASIL, Lei no 9.394, de 20 de dezembro de 1996. Lei de Diretrizes e Bases da Educação Nacional, Estabelece as diretrizes e bases da educação nacional. Brasília, DF, 1996.

BRASIL. Decreto no 9.057, de 25 de maio de 2017. Regulamenta o art. 80 da Lei no 9.394, de 20 de dezembro de 1996, que estabelece as diretrizes e bases da educação nacional. Presidência da República. Casa Civil, 2017.

CAMPOS, M. Multinacional do ensino abocanha lucro exorbitante com aporte público. Hora do Povo, 2014. Disponível em:

http://www.horadopovo.com.br/2014/05Mai/3247-09-05-2014/P4/pag4a.htm. Acesso em: 12 jun. 2017.

CARA, D. Campanha Nacional Pelo Direito a Educação [entrevista à EM.com]. Disponível em:

http://www.em.com.br/app/noticia/economia/2014/05/04/internas_economia,525098/f aculdades-que-recebem-recursos-do-fies-reajustam-precos-acima-da-inflacao.shtml. Acesso em: 20 maio 2018.

\section{CHAGAS, C. L. A expansão do ensino à distância no Brasil durante o Governo} LULA, 2013. Disponível em:

http://www.joinpp.ufma.br/jornadas/joinpp2015/pdfs/eixo13/a-expansao-do-ensino-adistancia-no-brasil-durante-o-governo-lula.pdf. Acesso em: 02 jul. 2017.

DINHAM, S. The worst of both worlds: How the U.S. and U.K. are influencing Disponível em: http://www.uab.mec.gov.br/. Acesso em 16 maio de 2017. 


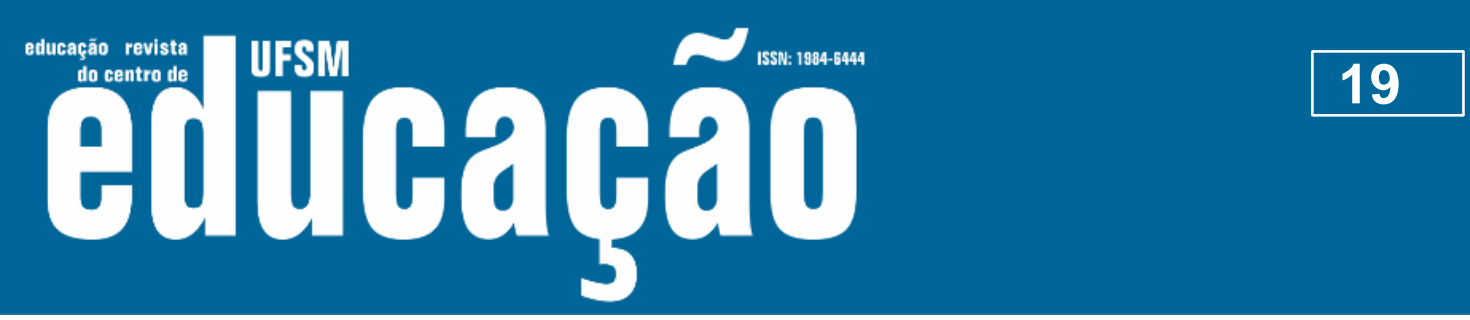

ISSN:1984-644 | http://dx.doi.org/10.5902/1984644435216

HALL, D.; GUNTER, H. M. A nova gestão pública na Inglaterra: a permanente instabilidade da reforma neoliberal. Educ. Soc., Campinas, v. 36, nํ. 132, p. 743758, jul.-set., 2015.

KROTON EDUCACIONAL. Histórico. 2017, Disponível em: http://www.kroton.com.br/. Acesso em: 07 jun. 2017.

LIMA, Kátia. Contrarreforma da educação superior e formação profissional em Serviço Social. Temporalis - Revista da Associação Brasileira de Ensino e Pesquisa em Serviço Social. Brasília: ABEPSS, n. 15, 2008.

MALANCHEN, J. As políticas de formação inicial a distância de professores no Brasil: democratização ou mistificação? Dissertação de Mestrado (Educação) Universidade Federal de Santa Catarina. 2007.

MICHAELIS ON LINE. Significado de Empiria. 2017. Disponível em:

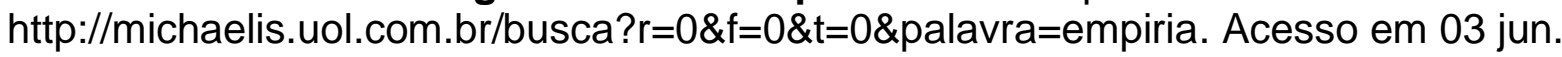
2017.

NUNES, C. P.; SILVA, J. B. da. Políticas de formação de professores na modalidade da educação a distância no Brasil: uma análise histórica. In: CONGRESSO BRASILEIRO DE ENSINO SUPERIOR A DISTANCIA. 11. Florianópolis. Anais...Florianópolis, ESUD, 2014.

OLIVEIRA J. J. ROSTÁS, Renato. Receita líquida da Kroton cresce 35\% no trimestre. Valor Econômico on line. 2014. Disponível em: https://www.valor.com.br/empresas/3539662/receita-liquida-da-kroton-cresce-35-notrimestre. Acesso em 12 jun. 2017.

PINTO, I. M. Políticas públicas: Caminhos para a EAD. 2017. In: COLOQUIO DESAFIOS, UFMG, Belo Horizonte. [apresentação palestra slides]. Disponível em: https://www.ufmg.br/ead/coloquiodesafios/Apresentacao/Pol\%C3\%ADticasP\%C3\%B Ablicas.pdf. Acesso em 09 julho 2017.

POMPEU, C.L A; FRAZAO, H. Lista de maiores financiadores expõe laços econômicos e políticos. Estadão on line. 2016. Disponível em: http://politica.estadao.com.br/noticias/geral,lista-de-maiores-financiadores-expoelacos-economicos-e-politicos,10000078203. Acesso em: 05 jun. 2017.

SAVIANI, D. O vigésimo ano da LDB: as 39 leis que a modificaram. Revista Retratos da Escola, Brasília, v. 10, n. 19, p. 379-392, jul./dez. 2016. Disponível em: http//www.esforce.org.br. Acesso em 02 jul. 2016. 


\section{ussm Eutua

ISSN:1984-644 | http://dx.doi.org/10.5902/1984644435216

SAVIANI, D. Pedagogia histórico-Crítica: primeiras aproximações. 5 ed. Campinas SP: Editores associados, 1995.

SCHNEIDER, G. Centralização, descentralização ou desconcentração: um olhar sobre a realidade Chilena e Brasileira. [s.I, s.n], 2014.

UNESCO. Estrategia a Mediano Plazo 2002-2007. Contribuir a la Paz y al Desarrollo Humano en la Era de la Globalización a través de la Educación, la Ciencia, la Cultura y la Comunicación (31C/4), París: UNESCO, 2001.

UNESCO. Marco de Ação de Dakar sobre Educação para todos: Cumprimento de nossos compromissos coletivos, adotado pelo Fórum Mundial de Educación, Dakar, Senegal, 26-28 de abril 2000, Paris: UNESCO.

UNIVERSIA. EAD Corresponderá a $51 \%$ do mercado em 2023. 2014. Disponível em: http://noticias.universia.com.br/educacao/noticia/2016/10/18/1144687/ead-brasilcorrespondera-51-mercado-2023-diz-pesquisa.html\#. Acesso em 02 maio 2017.

VERGER, A.; BONAL, X.; ZANCAJO, A. Recontextualizacion de políticas (cuasi) mercados educativos un análisis de las dinâmicas de demanda y oferta escolar em chile. Arquivos analíticos de políticas educativas. v. 24, n.27, 2016. Disponível em: http://www.redalyc.org/articulo.oa?id=275043450052. Acesso em: 19 jun. 2017.

WINDLE, J. A. the burdens of Marketized schooling in Australia. Privatization and the Education of Marginalized Children: Policies, Impacts and Global Lessons, p. 161, 2017.

\section{Correspondência}

Miriam de Cassia do Carmo Mascarenhas Mattos - Universidade do Estado de Santa Catarina, 2007, Centro de Educação a Distância, Avenida Madre Benvenuta, Itacorubi, CEP 88035-001, Florianópolis, Santa Catarina, Brasil.

\section{Notas}

1 A pesquisa bibliográfica faz uso de artigos, teses, dissertações, livros, entre outros materiais disponíveis, escritos por autores sobre o tema a ser analisado. Pode-se, assim, verificar o que já foi produzido em estudos anteriores a respeito do assunto. Para coleta dos materiais base desta pesquisa utilizou-se a base de dados da Scopus. Mas também buscamos vários sites para complementar informações e sustentar alguns argumentos e análises.

2 O levantamento, leitura e análise foram realizados entre maio e dezembro de 2018. Alguns dados foram atualizados em outubro de 2019. 


\section{Z Usm Ellibahá}

ISSN:1984-644 | http://dx.doi.org/10.5902/1984644435216

${ }^{16}$ Como a instalação, em 1972, da Comissão de Especialistas para estudar a possível implantação de experiência semelhante à da Universidade Aberta da Inglaterra no Brasil - Open University, ou ainda a constituição do Grupo de Trabalho instituído pela Portaria ministerial ํo 418/1988, que elaborou o documento "Por uma Política Nacional de Educação Aberta e a Distância", que estabelecia estratégias de implantação, acompanhamento e avaliação da EaD no Brasil. (PINTO, 2017).

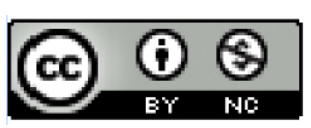

This work is licensed under a Creative Commons Attribution-NonCommercial 4.0 International (CC BY-NC 4.0) 